\title{
THE JARVIK 2000 OXFORD SYSTEM: INCREASING THE SCOPE OF MECHANICAL CIRCULATORY SUPPORT
}

\author{
S. Westaby, FRCS ${ }^{\mathrm{a}}$ \\ T. Katsumata, MD $^{\mathrm{a}}$ \\ R. Evans, $\mathrm{MD}^{\mathrm{a}}$ \\ D. Pigott, $M^{\mathrm{a}}$ \\ D. P. Taggart, FRCS \\ R. K. Jarvik, $\mathrm{MD}^{\mathrm{b}}$
}

\begin{abstract}
Methods: We developed a system for mechanical circulatory support based on the Jarvik 2000 intraventricular axial flow impeller pump (Jarvik Research, Inc., New York, N.Y.) and percutaneous electric power. The adult pump provides flow at a rate up to $10 \mathrm{~L} / \mathrm{min}$ with an energy requirement of 7 to 10 watts. The device was implanted into the apex of the left ventricle through a left thoracotomy without cardiopulmonary bypass. A Dacron graft conveyed blood to the descending thoracic aorta. In patients, we will use a skull-mounted carbon pedestal to transmit fine electric wires through the scalp skin. Being highly vascular, the scalp skin is resistant to infection. Results: We tested 16 adult systems and one pediatric system in 17 adult ewes weighing between 60 and $90 \mathrm{~kg}$. Five died of perioperative complications. Twelve survived between 3 and 198 days (mean 44 days) with a functioning device. None of the sheep could receive adequate anticoagulation with warfarin (INR 1.0 to 1.5). Acute thrombotic occlusion occurred after a 3-hour power loss in one device (46 days) but was cleared with streptokinase. In a second animal with endocarditis, the pump inflow became occluded with vegetations. No other device-related problems or important hemolysis developed despite pump speeds between 10,000 and $18,000 \mathrm{rpm}$. Renal function remained normal in all animals. Autopsy studies showed no pannus ingrowth at the device inflow despite the restrictive left ventricular cavity size. No sign of thromboembolism could be detected in the brains or kidneys. Conclusion: Our findings indicate the Jarvik 2000 Oxford System to be a safe and effective circulatory assist device. Potential uses include permanent circulatory support, bridge to transplantation, or bridge to myocardial recovery in acute or chronic left ventricular failure. (J Thorac Cardiovasc Surg 1997;114:467-74)
\end{abstract}

$W$ ith the proportion of elderly persons in the population increasing, heart failure is consuming enormous health care resources. Because of a severely restricted donor pool and a 5-year mortality of $40 \%$, cardiac transplantation can no longer be considered to address the problem. ${ }^{1,2}$ Mechanical blood pumps were first used clinically in the post-

From the Oxford Heart Centre, Oxford, United Kingdom, ${ }^{\mathrm{a}}$ and Jarvik Research, Inc., New York, N.Y.

Financial support provided by the Sir Kirby Laing, Bernard Sunley, and James Marshall Trusts.

Received for publication August 19, 1996; revisions requested Dec. 5, 1996; revisions received Jan. 23, 1997; accepted for publication Feb. 25, 1997.

Address for reprints: Stephen Westaby, FRCS, Oxford Heart Centre, John Radcliffe Hospital, Oxford, OX3 9DU, United Kingdom.

Copyright $(1997$ by Mosby-Year Book, Inc.

$0022-5223 / 97 \$ 5.00+0 \quad \mathbf{1 2} / \mathbf{1} / \mathbf{8 1 4 8 0}$ cardiotomy setting, and their use was extended to bridge to transplantation. The critical shortage of donor hearts resulted in prolonged left ventricular support and the crucial finding that in some patients the myocardium showed the propensity to recover. ${ }^{3,4}$ Bridge to recovery by mechanical off-loading offers a new approach to the treatment of heart failure, reminiscent of prolonged bed rest advocated by Burch and DePasquale ${ }^{5}$ in the 1960 s. Earlier application before the onset of wasting and multisystem failure may avert the need for transplantation in some patients.

Recently, the encouraging patient release programs with the Thermo Cardiosystems, Inc. (Woburn, Mass.) and Novacor (Baxter Healthcare Corp., Novacor Div., Oakland, Calif.) left ventricular assist devices (LVADs) in the United States have led to permanent implants for persons who are not candidates for transplantation in Europe. ${ }^{6}$ Although 


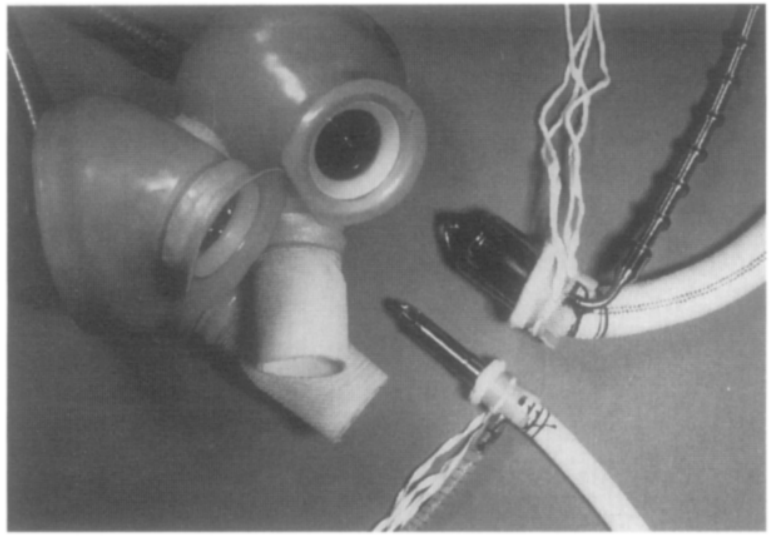

Fig. 1. The Jarvik 2000 axial flow impeller pump (adult and pediatric) with ventricular cuff compared with the Jarvik 7 total artificial heart.

these models are effective in this context, they are contraindicated for patients with less than $1.5 \mathrm{~m}^{2}$ body surface area, thus excluding small women and children. ${ }^{7}$ The stiff, percutaneous abdominal power line is a permanent infection risk, and removal of the LVAD is difficult when the patient's own heart is to be preserved. Efforts are therefore directed toward the design of a less obtrusive blood pump for widespread use in the various settings of acute and chronic heart failure. ${ }^{8,9}$ A fully implantable system with transcutaneous power through induction coils will not be realized for some time. Consequently, we have developed a system based on the Jarvik 2000 intraventricular impeller pump (Jarvik Research, Inc., New York, N.Y.) and a skull-mounted percutaneous carbon pedestal to transmit the power line. The size of the pump itself has been further reduced for use in infants and patients with acute myocardial infarction.

\section{Materials and methods}

The device and electrical system of the Jarvik 2000 device is an axial flow impeller pump that is inserted through a cuff into the apex of the left ventricle (Fig. 1). An impervious Dacron graft conveys blood to the descending thoracic aorta (Fig. 2, $A$ ). The adult model measures $2.5 \mathrm{~cm}$ in diameter by $5.5 \mathrm{~cm}$ in length. The weight is $85 \mathrm{gm}$ and the displacement volume $25 \mathrm{ml}$. The pediatric device measures $1.4 \mathrm{~cm}$ in diameter by $5 \mathrm{~cm}$ in length and is one fifth the size of the larger model. The weight is $18 \mathrm{gm}$ and the displacement volume $5 \mathrm{ml}$. The electromagnetic pump consists of a rotor with impeller blades encased in a titanium shell and supported at each end by tiny blood-immersed ceramic bearings less than 1 $\mathrm{mm}$ in diameter. The rotor is the sole moving part of the device. The impeller is powered by an electromagnetic field across the motor air gap, through which the blood flows. All blood-contacting surfaces are titanium. Power is delivered by a fine percutaneous wire and regulated by a pulse width-modulated, brushless, direct-current motor controller to determine motor speed. For the sheep devices, motor speed was at a fixed rate determined by the controller. (For the human model the motor rate will be responsive to heart rate and adjustable by the patient according to activity level.)

At the site of exit through the skin, the fine electric cable is transmitted through a pyrolytic carbon button which, in patients, will be secured to the skull (Fig. 2, B). The combination of immobility and highly vascular scalp skin is known to resist infection in a percutaneous system for artificial hearing (Fig. 3). In vitro studies using a water glycerol test solution to simulate blood viscosity show the adult device to provide a flow rate of up to $10 \mathrm{~L} / \mathrm{min}$ at $18,000 \mathrm{rpm}$. At normal operating speeds of 10,000 to $16,000 \mathrm{rpm}$, flow rates of between 4 and $6 \mathrm{~L} / \mathrm{min}$ are obtained at a mean aortic pressure of $80 \mathrm{~mm} \mathrm{Hg}$ with a power requirement of 7 to 10 watts. ${ }^{8}$ The device is inaudible to the unassisted ear but can be heard with a stethoscope.

The animals. The adult ovine model was chosen in an attempt to extend survival beyond 6 months (the realistic experimental life span of calves in the Texas Heart Institute experiments). ${ }^{9}$ For the adult device, 16 Welsh mule sheep between 3 and 5 years of age and weighing between 80 and $90 \mathrm{~kg}$ were used. For the "pediatric" pump implant the sheep weighed $60 \mathrm{~kg}$. The surgical procedures and postoperative care were humanely undertaken by licensed personnel in compliance with Home Office (U.K.) guidelines. The animals were anesthetized with fentanyl, intubated, and their lungs ventilated with an inspired oxygen fraction of $100 \%$. Two triple-lumen venous catheters were introduced by cutdown on the left internal jugular vein, and a fine arterial catheter was introduced into the left common carotid artery. Arterial and venous blood pressures, together with the electrocardiogram, were monitored continuously. Lidocaine infusion and boluses of bretylium were used to suppress left ventricular irritability during manipulation. Injections of the $\beta$-blocker labetalol were used to lower the blood pressure during aortic side clamping.

The operation. The sheep were positioned for a left thoracotomy. The seventh rib was removed to provide access to the left ventricular apex without excessive cardiac displacement. The power cable with a Dacron velour-covered carbon pedestal was tunneled under the scapula toward the midline and brought through the skin at the base of the neck. After intravenous antihypertensive therapy with labetalol was begun, 10,000 units of heparin was administered and an aortic side clamp applied. The preclotted $16 \mathrm{~mm}$ woven Dacron graft attached to the outflow of the Jarvik 2000 device was anastomosed to a longitudinal aortotomy with continuous 4-0 Prolene sutures (Ethicon, Inc., Somerville, N.J.). The graft was clamped and the aortic side clamp removed. The pericardium was then opened wide and suspended by sutures from the wound edges. Access to the left ventricular apex was improved by placing a swab behind the heart. The silicone-reinforced Dacron sewing cuff was sutured around the pointed left ventricular apex with between 12 


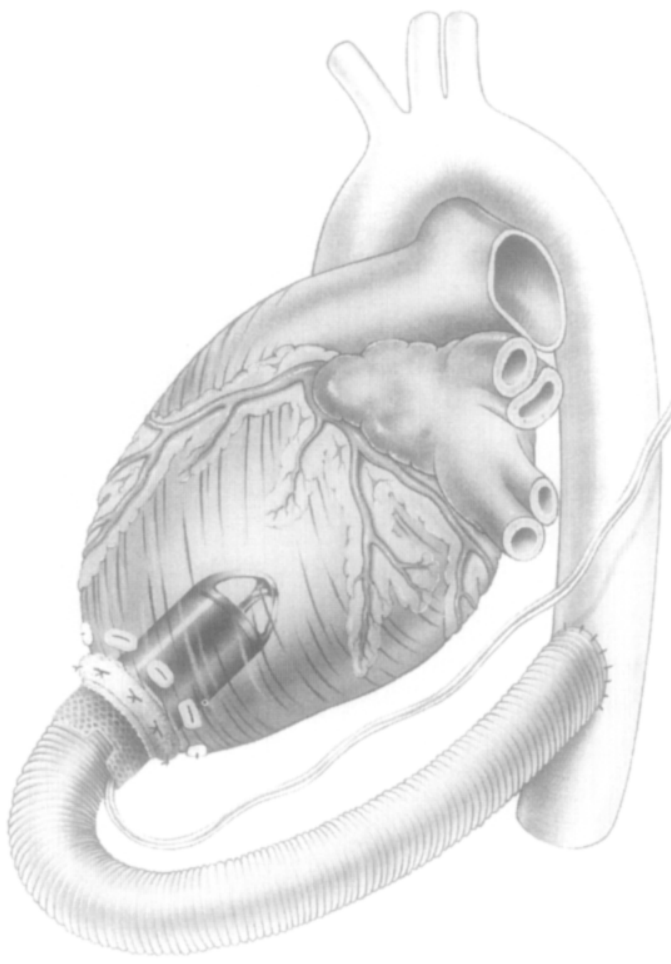

A

Fig. 2. A, The Jarvik 2000 Oxford System comprising pump, vascular graft, and percutaneous electrical system. B, The small electric cable is transmitted through the skin by way of a carbon pedestal screwed to the outer table of the skull to prevent movement.

and 15 2-0 Ethibond mattress sutures (Ethicon) supported with Teflon pledgets. Lidocaine (1\%) was injected directly into the apical muscle before the excisional left ventriculotomy with a cork-bore type of coring knife. Blood loss through the open apex was controlled by rapid insertion of the pump through the sewing cuff and into the left ventricle. Uncrossmatched blood transfusion from donor sheep was used if required. The device was secured in the correct position by tying down umbilical tape purse-string ties integral with the sewing ring. The saline-filled outflow graft was vented to remove residual air and the pump was switched on. In the event of ventricular fibrillation during apical manipulations, specially constructed elongated defibrillating paddles were applied to defibrillate. When hemodynamic stability was achieved, heparin was reversed

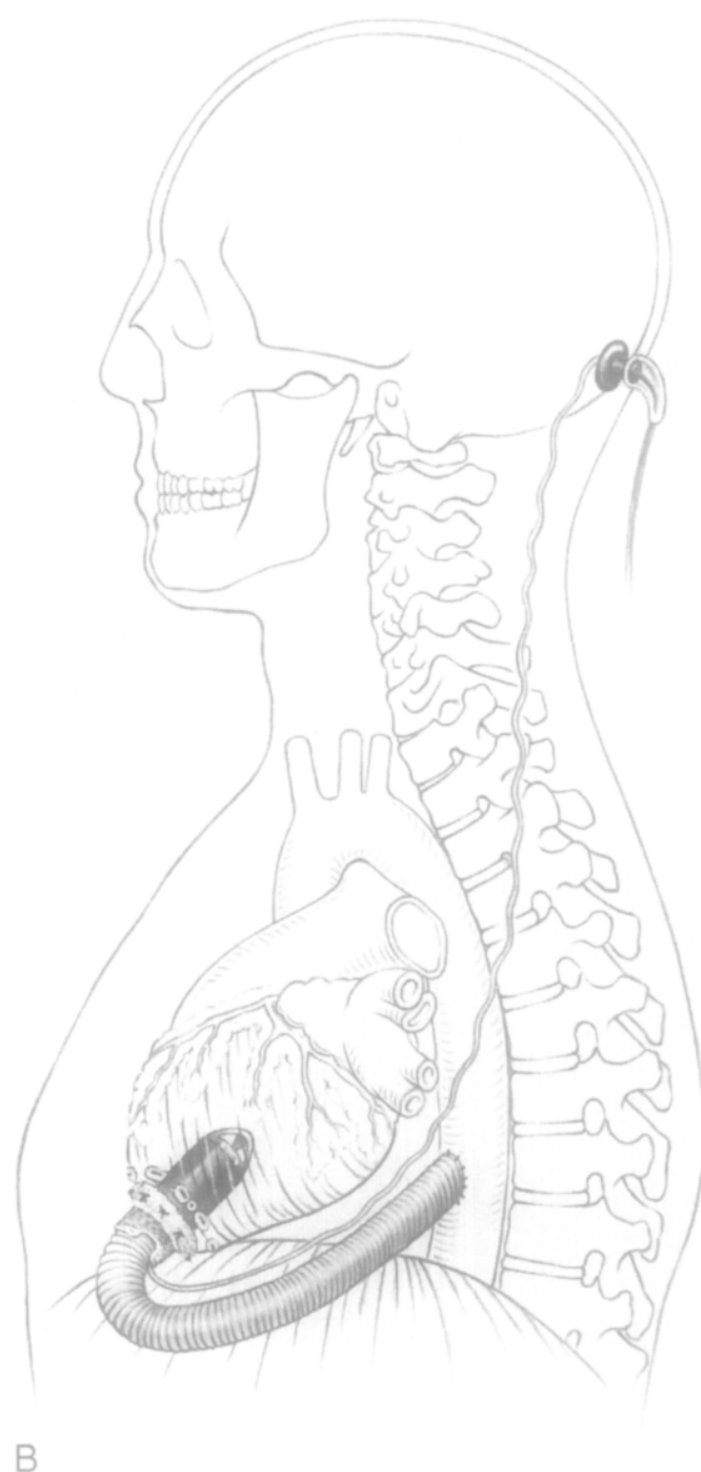




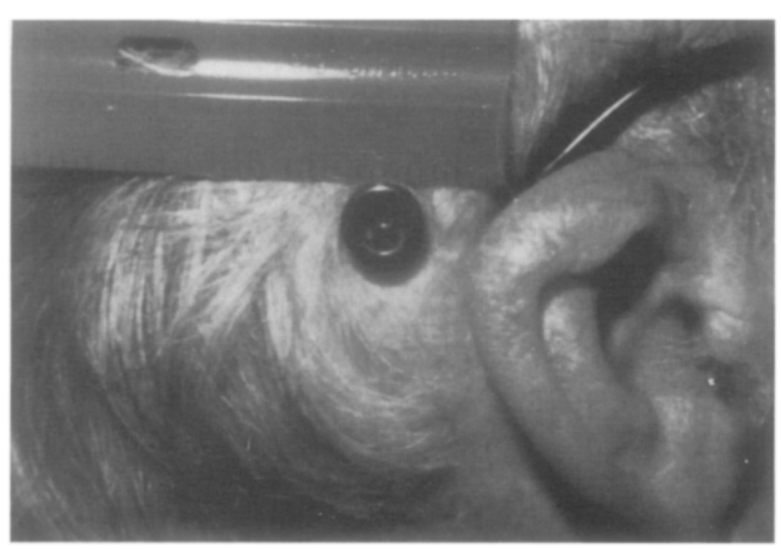

Fig. 3. Carbon pedestal 15 years after implantation for artificial hearing.

return and prevent opening of the aortic valve was tested by turning the device off and then progressively increasing the pump speed (up to $10 \mathrm{~L} / \mathrm{min}$ ) until the arterial pressure wave disappeared (Fig. 4). Battery power was used in six of the sheep to simulate the use of the device in patients.

During the course of the experiments each device was maintained at a continuous speed of 10,000 to $12,000 \mathrm{rpm}$, with a calculated (nomogram) flow rate from 4 to $6 \mathrm{~L} / \mathrm{min}$. The system controller and electric cables were attached to a specially designed vest around the animal's back and forelegs (Fig. 5). All animals were free to move around the pen with battery or mains power conveyed through an overhead electric cable attached to a fixed swivel apparatus. Most animals were able to drink and eat hay and concentrates within 24 hours of the operation.

The pump and electrical system were checked twice daily by auscultation and recording of pump speed and power consumption. Power consumption was determined by recording voltage and amperes. These were recorded graphically from day to day to identify differences. The relationship between pump speed and flow has been published previously. ${ }^{8}$ We did not use implantable flowmeters in our animals. Aspirin $75 \mathrm{mg}$ daily and warfarin 20 mg daily were commenced on the second postoperative day. Intramuscular analgesics were administered twice daily for 72 hours and thereafter for a specific indication. After removal of the arterial line, the pump function was monitored electrically and by auscultation. At weekly intervals, blood samples were obtained by percutaneous puncture from the internal jugular vein and assayed for full blood count, electrolytes, and indices of hemolysis including plasma-free hemoglobin and lactate dehydrogenase.

Autopsy studies. Autopsy was undertaken immediately after death and the cause of death was identified. The device was removed from the left ventricle and disassembled to look for thrombus formation. The heart, lungs, brain, kidneys, and liver were carefully examined for macroscopic evidence of thromboembolism. Slices of brain and kidney were examined histologically.

\section{Results}

Five deaths caused by arrhythmia or bleeding occurred within 24 hours of the operation. These procedures played an important part in the surgical learning curve. The intraoperative cardiac manipulations, particularly ventricular coring, provoked ventricular fibrillation in seven of the 17 animals. Conventional human defibrillating paddles were ineffective, and elongated paddles were designed. We eventually found that bretylium, given to reduce the likelihood of fibrillation during coring, initially caused supraventricular tachycardia. This predisposed to ventricular fibrillation when given within 15 minutes of ventricular coring. In later animals this problem was overcome by infusing bretylium shortly after anesthetic induction. No late deaths from ventricular fibrillation were attributable to the position of the device within the ventricle. Three of the five deaths within 24 hours were a direct result of refractory ventricular fibrillation and two were due to bleeding from the left internal thoracic artery and aortic anastomosis, respectively. One animal required urgent reintubation when the rumen contents were regurgitated into the airway. A second sheep was resuscitated for this problem without reintubation. Three other sheep died of secondary hemorrhage from the aorta between the third and fifth postoperative days. These animals had initially made a straightforward postoperative recovery and were feeding normally. Bleeding was probably caused by severe hypertension at the time of removal of the arterial line from the neck. In all of these sheep the device functioned well and was free from thrombus or blood clot at the time of autopsy. Modifications in technique avoided these complications in subsequent animals. Two sheep died suddenly at 12 and 22 days, respectively, of delayed aortic rupture, not at the anastomosis but at the site of side clamp application. Both devices were clean.

Three animals were put to death at 34,42 , and 48 days because of chronic infected hemothorax $(n=2)$ or drive-line infection (without the carbon pedestal). One of these animals had endocarditis with vegetations on the device and vascular graft. In this animal the power line had been fractured at the skin level 10 days before death, and the device was not functioning for 8 hours before repair. This may have accounted for thrombus in the pump and graft when the animal was put to death. The pumps were uninfected and clean in the other two. Four sheep are long-term survivors, alive between 6 weeks and 7 months (198 days) 


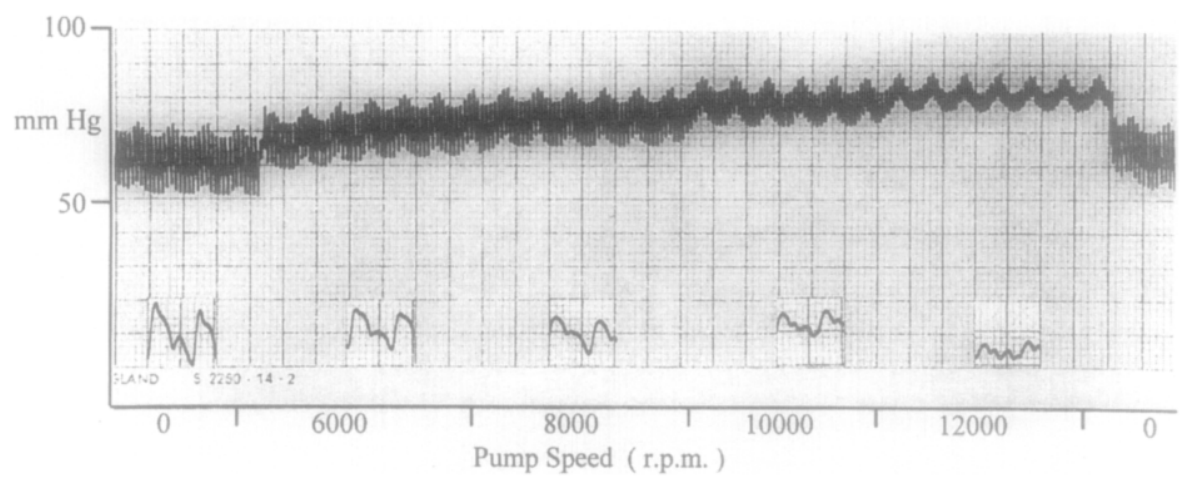

Fig. 4. Capture of all mitral valve flow by the intraventricular pump so that the aortic valve does not open.

after the operation. Three have the adult device and one a miniaturized pediatric system. In each case the device is working satisfactorily. No device-related deaths have occurred.

Pump function. At the continuous speed of $10,000 \mathrm{rpm}$ the mean voltage requirement and amperage for the adult device were 14 volts and between 50 and 150 milliamperes, respectively. The device was able to capture all the flow through the mitral valve, providing pulseless flow at speeds exceeding $12,000 \mathrm{rpm}$, at which point the mean arterial pressure was between 80 and $90 \mathrm{~mm} \mathrm{Hg}$. No adverse reaction occurred in the animals when blood flow changed from pulsatile to nonpulsatile. At 10,000 rpm, arterial pulse pressure remained in the region of $20 \mathrm{~mm} \mathrm{Hg}$ but correlated with changes in pump current. Natural ventricular contraction provided a differential pressure load on the pump, and the torque load on the motor varied with pulse pressure. This variation in preload corresponding to native heart function provided pulsatile flow. When the device was turned off during battery changes, the temporary reversal of graft flow (functional aortic insufficiency) was well tolerated by the animals.

With the device running, we have not encountered clotting or thromboembolism. When a second pump lost electrical power for 3 hours, presumed thrombosis prevented the restart. Thrombolysis with streptokinase, together with heparinization, restored normal pump function by electrical and auscultatory parameters. The sheep remained well throughout and survived for 198 days.

The sheep's rumen precludes reliable anticoagulation, even with very high doses of warfarin. Most INR (international normalized ratio) results were between 1.0 and 1.5 and most animals had no measurable anticoagulation for most of their follow-up period.
Early minor elevations of lactate dehydrogenase and free hemoglobin between 1 and 4 weeks after the operation may have resulted from the sequelae of uncrossmatched blood transfusion, drug administration, or resolution of intrathoracic hematoma after the operation. Alternatively, early hemolysis could have been related to the device or vascular graft, but no clinical or biochemical evidence for hemolysis was detected in long-term survivors.

Autopsy studies. Presence of the device did not promote endothelial overgrowth or intracavity thrombus formation, even though the sheep were not given anticoagulants.

On gross pathologic examination, two animals had diffuse consolidation in the left lung. Histologic examination revealed chronic inflammatory changes in the lungs with active bacterial infection, which were consistent with their intermittent fever and respiratory distress. No abnormalities were detected in the brain or liver in any animal. In extensive (5 $\mathrm{mm}$ ) histologic sections of the kidneys from seven animals that survived for more than 1 month, we found no evidence of thromboembolism, infarction, or infection.

\section{Discussion}

The animal model. Recovery after major cardiovascular operations is difficult in the sheep model. Whereas calves tolerate surgical procedures well, the bovine model is restricted in longevity by rapid growth. We therefore decided to pursue the adult sheep model, and with increasing experience the length of survival improved. Our early problems with ventricular fibrillation were overcome by changing the time of bretylium administration. The problem of aortic rupture was thought to be the result of tissue fragility and was addressed by ob- 


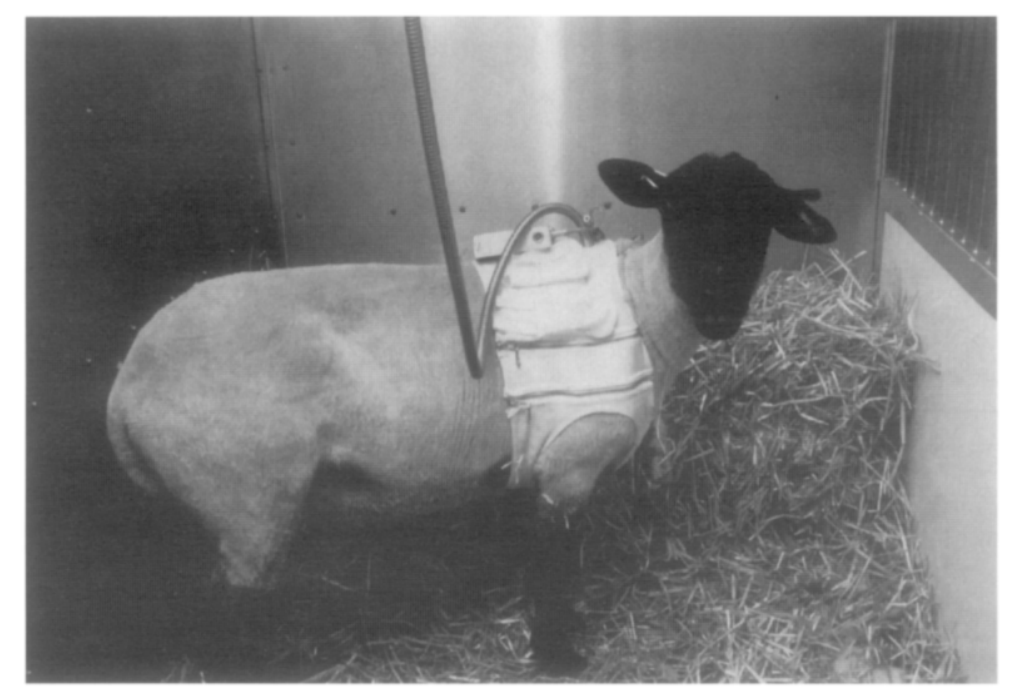

Fig. 5. Sheep, 6 months after implantation, wearing a vest with a controller and swivel electric cable connection.

taining younger animals. Until this point we had been supplied with 5 -year-old ewes that had been removed from the breeding stock. The younger ewes had perceptibly better tissues.

We elected to avoid cardiopulmonary bypass despite the need to suture and core out the left ventricular apex while the heart supported the circulation. The sheep heart is thick walled and irritable, with a small ventricular cavity (Fig. 6). The adult Jarvik 2000 device completely fills the left ventricular apex, and it was important to align the inflow of the pump with the mitral valve orifice. Despite the ventricular irritability during direct manipulations, the presence of the device within the ventricle did not cause death through late arrhythmia.

Kaplon and colleagues ${ }^{8}$ (Columbia Presbyterian Medical Center) implanted a smaller prototype device $(1.8 \mathrm{~cm}$ diameter, $5 \mathrm{~cm}$ length, $45 \mathrm{gm}$ weight, displacement volume $12 \mathrm{ml}$ ) into seven sheep using cardiopulmonary bypass in four. ${ }^{8}$ Two animals died in the early postoperative period, but five survived $57 \pm 18$ days. Neither thromboembolic complications nor hemolysis developed in these animals, and mean hematocrit values rose significantly with time. Macris and coworkers $^{9}$ (Texas Heart Institute) implanted a prototype of the larger model ( $25 \mathrm{ml}$ volume, $85 \mathrm{gm}$ ) into seven calves, which were supported for between 40 and 162 days. ${ }^{9}$ The animals were successfully given with warfarin, dipyridamole, and aspirin. Again, device-related hemolysis was minimal, and thrombus occurred in only one device, after which the rotor/stator junction was redesigned. The Oxford device is a later model based on the initial experience from these centers.

The Jarvik 2000 Oxford System (Jarvik Research, Inc., New York, N.Y.). A system for human use has evolved during the course of these experiments (Fig. 2 ). This consists of the pump with an outflow Dacron graft (Hemashield, Meadox Medicals, Inc., Oakland, N.J.) for anastomosis to the descending thoracic aorta. Electrical wires will be brought out by way of the apex of the chest through the neck to the base of the skull, where a percutaneous, pyrolytic carbon pedestal will transmit fine electrical wires through the skin of the scalp. The carbon pedestal is screwed to the outer table of the skull for complete immobility. The scalp is highly vascular and resistant to infection. A similar approach with artificial ear technology has been successful with very low infection rates for more than 15 years. A compact system controller is located externally in a vest or belt, together with lightweight batteries.

The critical feature of the Jarvik 2000 design is that a high-flow stream of blood washes the tiny bearings continuously and prevents thrombus formation. After removal of the device, examination of the bearings showed virtually no wear. None of the three experimental centers has documented significant hemolysis or thromboembolism from the pump. In the animal with endocarditis in the current series, the inflow of the device was occluded by vegetations but little thrombus was found in the outflow. 
The principal objective of these experiments was to address the safety, durability, and potential for thromboembolism or hemolysis. We have established mechanical reliability, remarkably little hemolysis, and freedom from thrombosis for up to 7 months in an animal model in which reliable anticoagulation is virtually impossible. Lack of perceptible noise is also a great advantage in comparison with existing pusher-plate LVADs. The smaller pediatric device continued to function satisfactorily 20 weeks after implantation. With the capacity to pump at a rate of $3 \mathrm{~L} / \mathrm{min}$, this model can be used in infants with heart failure or in patients with myocardial infarction complicated by cardiogenic shock.

Clinical potential for the Jarvik 2000 Oxford System. Our aim is to produce a realistic, temporary or permanent substitute for the left ventricle suitable for use in both acute and chronic heart failure. Long-term off-loading of the left ventricle with existing LVADs during bridge to transplantation has resulted in an element of myocardial recovery, particularly in patients with dilated cardiomyopathy., ${ }^{3,4}$ In Europe, removal of the LVAD in preference to transplantation has led to the concept of mechanical bridge to recovery. However, whereas removal of the existing LVADs is feasible in the transplant setting, where the native heart is excised, we have found removal of the Thermo Cardiosystems LVAD and conservation of the recovered ventricle to be technically challenging.

In contrast to the electric pusher-plate LVADs, the compact axial flow impeller pump is silent, easily implantable, and unobtrusive. The intraventricular position conveys distinct advantages. The device is practically encapsulated by the native myocardium so that infection is unlikely. There is no inflow graft at risk for thrombus formation. Unlike the larger, implantable LVADs, the Jarvik 2000 system does not need valves and can be used in patients of all sizes. ${ }^{10,11}$ Energy requirements are less than those of pusher-plate pumps, and an infection-resistant percutaneous electric cable has the advantage of simplicity and reliability. None of the animals with a percutaneous carbon pedestal had a drive-line infection even though the skin was freely mobile at the exit site.

This device has numerous potential uses, including permanent left ventricular support, bridge to cardiac transplantation, and bridge to left ventricular recovery. Given the incontrovertible shortage of transplant donors, the prospect of realistic, permanent mechanical circulatory support or circulatory

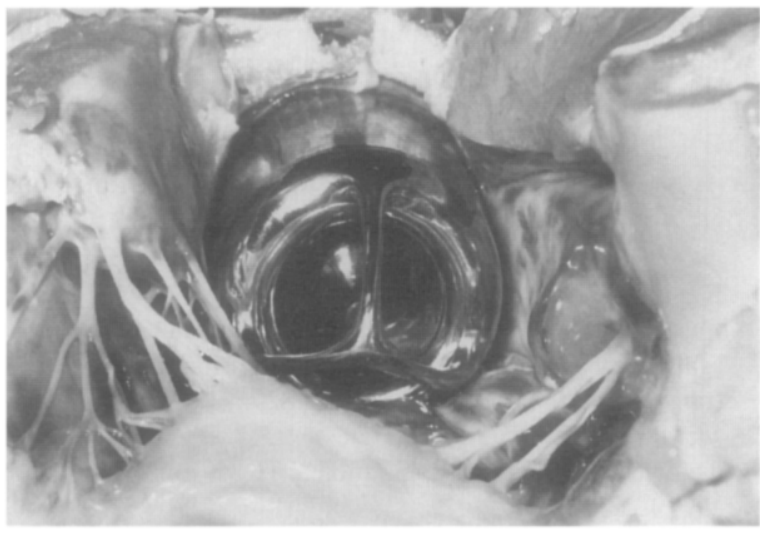

Fig. 6. Dissection of the sheep heart at autopsy showing the very thick left ventricular wall and small left ventricular cavity filled by the device.

support as a therapeutic option is compelling. Mueller and colleagues ${ }^{12}$ in Berlin have removed LVADs from patients with dilated cardiomyopathy who had been supported for $160,244,331$, and 347 days. Disappearance of the autoantibody against the $\beta_{1-}$ adrenergic receptor was used to time device explantation, and left ventricular recovery has been sustained. ${ }^{12}$ Two infants with acute viral myocarditis and ejection fractions less than $15 \%$ were resuscitated by implantation of biventricular assist devices and were successfully weaned at 25 and 31 days with ejection fractions of $55 \%$ and $65 \%$, respectively, thus avoiding transplantation. ${ }^{13}$ Morphologic, biochemical, and functional myocardial recovery has been demonstrated in hearts with dilated cardiomyopathy after prolonged LVAD support at the Texas Heart Institute and Columbia Presbyterian Hospital. These hearts were studied in detail at the time of LVAD implantation and after removal at transplantation. ${ }^{3,4}$ Similar findings have now been reported from Osaka, Japan, and Oxford, United Kingdom. ${ }^{14}$

Besides long-term support, the Jarvik 2000 device is suitable for the treatment of postcardiotomy left ventricular failure or acute myocardial infarction with cardiogenic shock. In this setting the infant device could be used to provide up to $3 \mathrm{~L}$ of blood flow to off-load the failing ventricle.

When the pacemaker was designed to treat problems of heart rhythm during cardiac operations 40 years ago, the real scope of the technology was unforeseen. It is only a matter of time before a blood pump emerges as a substitute for the left ventricle and becomes the mechanical equivalent to 
the pacemaker in heart failure. The Jarvik 2000 Oxford System approaches this goal.

Mr. Clifford Hansen and the staff of the Biomedical Services Unit provided invaluable technical assistance and expert humane care of the animals.

\section{REFERENCES}

1. Evans RW, Manninen DL, Garrison LP, Maier AM. Donor availability as the primary determinant of the future of heart transplantation. JAMA 1986;255:1982-6.

2. McManus RP, O'Hair DP, Deitziner JM, et al. Patients who die awaiting heart transplantation. $\mathbf{J}$ Heart Lung Transplant 1993;12:159-72.

3. Levin $\mathrm{HR}, \mathrm{Oz} M C$, Cher JM, Packer M, Rose EA, Burkhoff D. Reversal of chronic ventricular dilation in patients with end stage cardiomyopathy by prolonged mechanical unloading. Circulation 1995;91:2717-20.

4. Frazier $\mathrm{OH}$, Benedict $\mathrm{CR}$, Radovancevic B, et al. Improved left ventricular function after chronic left ventricular unloading. Ann Thorac Surg 1996;62:675-82.

5. Burch GE, DePasquale NP. On resting the human heart. Am J Med 1968;44:165-7.

6. Myers TJ, Dasse KA, Macris MP, et al. Use of left ventricular assist device in an outpatient setting. ASAIO J 1994;40:471-5.

7. Frazier OH, Rose EA, McCarthy P, et al. Improved mortality and rehabilitation of transplant candidates treated with a long term implantable left ventricular assist system. Ann Surg 1995;222:327-38.

8. Kaplon RJ, Oz MC, Kwiatkowski PA, et al. Miniature axial flow pump for ventricular assistance in children and small adults. J Thorac Cardiovasc Surg 1996;111:13-8.

9. Macris MP, Parnis SM, Frazier OH, Fugua JM, Jarvik RK. Development of an implantable ventricular assist system. Ann Thorac Surg 1997;63:367-70.

10. Frazier $\mathrm{OH}$, Macris MP, Myers TJ, et al. Improved survival after extended bridge to cardiac transplantation. Ann Thorac Surg 1994;57:1416-22.

11. McCarthy PM, Portner PM, Tobler HG, et al. Clinical experience with the Novacor ventricular assist system. J Thorac Cardiovasc Surg 1991;102:573-81.

12. Mueller J, Wallukat G, Weng Y, Hetzer R. Recovery from dilated cardiomyopathy and anti $\beta$, adrenoceptor auto-antibodies. Proceedings of the Sixth International Symposium on Artificial Heart and Assist Devices. Tokyo: 1996. Abstract 51.

13. Weng Y, Uhlemann F, Theodoridis V, et al. Therapy of acute myocarditis by implantation of a biventricular assist device in childhood. Proceedings of the Sixth International Symposium on Artificial Heart and Assist Devices. Tokyo: 1996. Abstract 34.

14. Nakatani T, Sasako $Y$, Kosakai $\mathrm{T}$, et al. Influence of long term support on the severely failed left ventricle. Proceedings of the Eighth International Symposium on Artificial Heart and Assist Devices. Tokyo: 1996. Abstract 53.

\section{Availability of Journal back issues}

As a service to our subscribers, copies of back issues of The Journal of Thoracic and Cardiovascular Surgery for the preceding 5 years are maintained and are available for purchase from Mosby at a cost of $\$ 15.00$ per issue until inventory is depleted. The following quantity discounts are available: $25 \%$ off on quantities of 12 to 23, and one third off on quantities of 24 or more. Please write to Mosby-Year Book, Inc., Subscription Services, 11830 Westline Industrial Drive, St. Louis MO 63146-3318, or call 800-453-4351 or 314-453-4351 for information on availability of particular issues. If unavailable from the publisher, photocopies of complete issues may be purchased from UMI, 300 N. Zeeb Rd., Ann Arbor, MI 48106, 313-761-4700. 